University of Wollongong

Research Online

Faculty of Engineering and Information

Faculty of Engineering and Information

Sciences - Papers: Part A

Sciences

$1-1-2017$

\title{
Simulation ballasted track behavior: numerical treatment and field application
}

\author{
Ngoc Trung Ngo \\ University of Wollongong, trung@uow.edu.au \\ Buddhima Indraratna \\ University of Wollongong, indra@uow.edu.au \\ Cholachat Rujikiatkamjorn \\ University of Wollongong, cholacha@uow.edu.au
}

Follow this and additional works at: https://ro.uow.edu.au/eispapers

Part of the Engineering Commons, and the Science and Technology Studies Commons

Research Online is the open access institutional repository for the University of Wollongong. For further information contact the UOW Library: research-pubs@uow.edu.au 


\title{
Simulation ballasted track behavior: numerical treatment and field application
}

\begin{abstract}
The load deformation of ballasted rail tracks subjected to cyclic loading is investigated experimentally using a large-scale track process simulation apparatus and numerically through a combined discrete element-finite-difference approach. Laboratory tests were performed to examine the deformation and degradation of ballast subjected to cyclic loading at $15 \mathrm{~Hz}$ and a lateral confinement of $10 \mathrm{kPa} 10 \mathrm{kPa}$. The laboratory results reveal that ballast undergoes significant deformation during the initial load cycles, followed by gradually increasing deformation attaining a steady value toward the end of testing. A numerical model based on a combined discrete element method (DEM) and finite-difference method (FDM) is introduced to study the load-deformation response of the ballast assembly while considering interaction between the ballast aggregates and the subgrade layer. In this coupled model, the discrete ballast grains are modeled by DEM, and the subgrade domain is modeled as a continuum by FDM. Interface elements are introduced to transmit the interacting forces and displacements between adjoining material domains in which the DEM transfers contact forces to the FDM, and then the FDM updates the displacements, which provides subsequent input into the DEM. This computational cycle continues with the increasing number of loading cycles. The numerical model is validated by comparing the predicted cyclic load-deformation response with the laboratory measurements. Contact force distributions and stress contours in the assembly are analyzed and presented graphically to interpret the behavior of the model track, and the effects that subgrade stiffness have on the axial strain and bond breakage of the ballast are investigated. This combined DEM-FDM analysis is also used to analyze the load deformation of an instrumented track in the town of Singleton, Australia, and the numerical predictions are compared with the field data.

Disciplines

Engineering | Science and Technology Studies

\section{Publication Details}

Ngo, N., Indraratna, B. \& Rujikiatkamjorn, C. (2017). Simulation ballasted track behavior: numerical treatment and field application. International Journal of Geomechanics, 17 (6), 04016130-1-04016130-12.
\end{abstract}




\section{Simulation of Ballasted Track Behaviour - A Numerical Treatment and Field Application}

Ngoc Trung Ngo, PhD, MEng, BEng

Lecturer, Centre for Geomechanics and Railway Engineering, Faculty of Engineering and Information Sciences, University of Wollongong, Wollongong, NSW 2522, Australia; ARC Centre of Excellence for Geotechnical Science and Engineering, Australia

\section{Buddhima Indraratna, PhD (Alberta), FIEAust., FTSE, FASCE}

Research Director, Distinguished Professor of Civil Engineering, Centre for Geomechanics and Railway Engineering, Faculty of Engineering, University of Wollongong, Wollongong, NSW 2522, Australia; ARC Centre for Excellence for Geotechnical Science and Engineering, Australia

\section{Cholachat Rujikiatkamjorn, $\mathrm{PhD}$, MEng, BEng}

Associate Professor, Centre for Geomechanics and Railway Engineering, Faculty of Engineering, University of Wollongong, Wollongong City, NSW 2522, Australia; ARC Centre for Excellence for Geotechnical Science and Engineering, Australia Faculty of Engineering, Australia

Technical paper, Submitted to ASCE- International Journal of Geomechanics

Author for correspondence:

Distinguished Professor B. Indraratna

Faculty of Engineering University of Wollongong

Wollongong, NSW 2522

Australia.

Ph: +61242213046

Fax: +61242213238

Email: indra@uow.edu.au 


\section{Simulation of Ballasted Track Behaviour - A Numerical Treatment and Field Application} Ngoc Trung $\mathrm{Ngo}^{1}$, Buddhima Indraratna ${ }^{2}$, and Cholachat Rujikiatkamjorn ${ }^{3}$

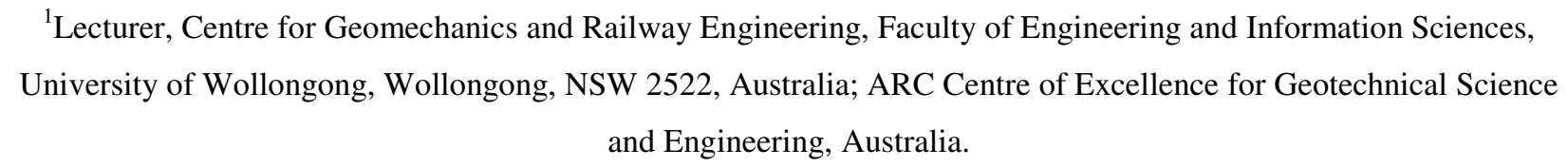

${ }^{2}$ Research Director, Distinguished Professor of Civil Engineering, Centre for Geomechanics and Railway Engineering, Faculty of Engineering, University of Wollongong, Wollongong, NSW 2522, Australia; ARC Centre for Excellence for Geotechnical Science and Engineering, Australia, Email: indra@uow.edu.au, Ph: +612 42213046 Fax: +61 242213238

\footnotetext{
${ }^{3}$ Associate Professor, Centre for Geomechanics and Railway Engineering, Faculty of Engineering and Information
} Sciences, ARC Centre of Excellence for Geotechnical Science and Engineering, University of Wollongong, Wollongong, NSW 2522, Australia. Email: cholacha@uow.edu.au, Ph: +61242215852 Fax: +61 242213238

The load-deformation of ballasted rail tracks subjected to cyclic loading is investigated experimentally using a large-scale track process simulation apparatus, and numerically through a combined discrete element-finite difference approach. Laboratory tests were carried out to examine the deformation and degradation of ballast subjected to cyclic loading at $15 \mathrm{~Hz}$ and a lateral confinement of $10 \mathrm{kPa}$. The laboratory results reveal that ballast undergoes significant deformation during the initial load cycles, followed by gradually increasing deformation attaining a steady value towards the end of testing. A numerical model based on combined discrete element method (DEM) and finite difference method (FDM) is introduced to study the load-deformation response of the ballast assembly while considering interaction between the ballast aggregates and the subgrade layer. In this coupled model, the discrete ballast grains are modelled by DEM and the subgrade domain is modelled as a continuum by FDM. Interface elements are introduced to transmit the interacting forces and displacements between adjoining material domains whereby the DEM transfers contact forces to the FDM, and then the FDM updates the displacements which provide a subsequent input to the DEM; this computational cycle continues with the increasing number of loading cycles. The numerical model is validated by comparing the predicted cyclic loaddeformation response with the laboratory measurements. Contact force distributions and stress contours in the assembly are analysed and presented graphically to interpret the behaviour of the 
model track, and the effects that subgrade stiffness have on the axial strain and bond breakage of the ballast are investigated. This combined DEM-FDM analysis is also used to analyse the loaddeformation of an instrumented track in Singleton and the numerical predictions are compared with the field data.

\section{Introduction}

Ballast is an essential component of rail track substructure that is commonly used to distribute the wheel load from sleepers to the underlying subgrade, maintain track alignment, and provide track drainage (Selig and Waters 1994; Indraratna et al. 2013). It normally consists of medium to coarse gravel sized particles $(10-53 \mathrm{~mm})$ and a small proportion of sand size grains. Upon repeated train loading these aggregates degrade to smaller sizes that seriously decrease the shear strength and impede the drainage capacity of the track substructure (Suiker et al. 2005; Indraratna et al. 2011a; Huang and Tutumluer 2011). It is widely believed that the deformation of ballasted tracks can be attributed to particle breakage followed by re-compaction and lateral spreading of aggregates (i.e. parallel to sleepers), in the absence of sufficient lateral confinement (Suiker and Borst 2003; Indraratna et al. 2011b; Anderson and Fair 2008). In an actual track, ballast settlement and lateral spreading progressively increase with increased train speeds and impact loads associated with wheel and rail irregularities. This results in excessive differential settlements which eventually alters the track geometry and causes instability (Lackenby et al. 2007; Anderson and Fair 2008).

Continuum approaches (e.g. finite element or finite difference method) have been used to model granular material assemblies, and various conventional continuum constitutive models have been introduced to capture the stress-strain behaviour of granular materials (e.g. Indraratna and Nimbalkar 2013). Due to the discrete nature of aggregates, the continuum approach cannot accurately capture their micromechanical behaviour governed by fabric anisotropy, contact force orientations, and localised strain. This is why the discrete element method (DEM) rather than continuum-based methods are increasingly used to study granular materials. DEM was first introduced by Cundall and Strack (1979) and has been widely applied to examine the mechanical behaviour of ballasted tracks (McDowell et al. 2006; Cui and O'sullivan 2006; Lobo-Guerrero and Vallejo 2010; Tutumluer et al. 2012; Ngo et al. 2014). DEM provides a deeper insight into the micromechanical characteristics of granular materials, such as the contact force distribution, fabric anisotropy, and particle breakage that are almost impossible or unlikely to be measured experimentally (McDowell and Harireche 2002; Lobo-Guerrero and Vallejo 2006; Cui and O'sullivan 2006; Bhandari and Han 2010; Ngo et al. 2016a). 
DEM has recently been used to model the cyclic load-deformation behaviour of ballast subjected to monotonic and cyclic loads. Indraratna et al. (2010) used DEM to model fresh ballast subjected to 1,000 load cycles to study the shear stress-strain and particle degradation under various load frequencies, while Lu and McDowell (2010) introduced a DEM model to simulate ballast subjected to 100 load cycles and found it could still capture the stress-strain behaviour of ballast. In these studies the loading was limited to only a few hundred load cycles, and the role of angularity with

113 regards to grains of various shapes and sizes could not be captured accurately. In addition, the high 114 computational cost of simulating a granular assembly with an extremely large number of particles may relegate DEM to practical (large scale) problems. For instance, Indraratna et al. (2014a) simulated a typical laboratory test on fouled ballast (e.g. a conventional direct shear test) and the computation time was almost 500 hours (using a high performance workstation) for just one simulation. Given the excessive cost of solving a particular problem in DEM, and the numerical inability to accurately model a large geometrical problem with different particle assemblies and layering, there is a need to develop a coupled discrete-continuum approach that would fully utilise both approaches with acceptable computational effort and reasonable accuracy.

The coupled DEM-FDM model proposed here utilises each numerical scheme to provide a realistic solution to model an integrated and layered ballasted track, and a mathematical framework representing ballast-subgrade interaction while considering subgrade stiffness and particle breakage is also introduced. The cyclic load and deformation of ballast measured in the laboratory are used to calibrate and validate the proposed model.

\section{Track Process Simulation Apparatus}

A novel large-scale Track Process Simulation Apparatus (TPSA) with a dynamic actuator (specimen size: $800 \mathrm{~mm} \times 600 \mathrm{~mm} \times 600 \mathrm{~mm}$ ) is used (Fig. 1) to test and monitor the deformation and degradation of ballast (Indraratna and Salim 2005; Indraratna et al. 2013). The ballast came

131 from Bombo quarry, New South Wales, Australia, and was then cleaned and sieved according to 132 Australian Standards (AS 2758.7, 1996); its average particle size is $d_{50}=35 \mathrm{~mm}$, which is similar to 133 current Australian practices in Queensland and New South Wales. To represent field conditions, a $134150 \mathrm{~mm}$ thick capping and subgrade layer made from a mixture of coarse sand and gravel was 135 placed at the bottom of the apparatus and compacted to a bulk unit weight of $18.5 \mathrm{kN} / \mathrm{m}^{3}$. Ballast was then placed above the capping layer (i.e. subballast) and compacted in $50 \mathrm{~mm}$ thick sublayers to a field unit weight of approximately $15.5 \mathrm{kN} / \mathrm{m}^{3}$, until the ballast layer was $300 \mathrm{~mm}$ high. 
provided by shoulder ballast. Meanwhile, lateral displacement in the direction of train passage was not allowed to simulate plane strain conditions, thus mimicking a straight track where ballast displacement in this direction is very small compared to lateral movement parallel to the sleepers (Indraratna et al. 2005; Ngo et al. 2016a). The four vertical walls of the apparatus were connected with a system of ball bearings and hinges which allowed them to displace laterally with minimum resistance. Cyclic loads were determined in accordance with Esveld (2001) where a maximum induced cyclic stress of $\sigma_{y y}=420 \mathrm{kPa}$ subjected to a frequency of $f=15 \mathrm{~Hz}$ was used to simulate a freight train with an axle load of 30 tonnes, travelling at approximately $90 \mathrm{~km} / \mathrm{h}$. All the tests continued to 500,000 load cycles. The results and analysis of these tests were presented earlier by Indraratna et al. (2013), and highlighted that the ballast settled rapidly within the first 100,000 load cycles, followed by a decreased rate of settlement up to 300,000 cycles, and then remained relatively unchanged towards the end of testing. Ballast breakage was also investigated in the laboratory by measuring the differences in the ballast particle size distribution curves before and after every test, using the ballast breakage index $(B B I)$ proposed earlier by Indraratna and Salim (2005). The test results are used here to calibrate and validate the coupled DEM-FDM model.

\section{Combined Discrete-Finite Difference Method}

A schematic geometric model of the combined discrete-finite difference (DEM-FDM) is illustrated in Fig. 2a, where the dimensions represent the large-scale TPSA. Given that the ballast displaced along the direction of train passage is very small due to confinement by the sleepers (ties), a coupled DEM-FDM analysis was carried out while assuming an equivalent plane strain condition that usually represents long and straight tracks. A ballast layer was modelled in DEM using the Particle Flow Code, PFC2D (Itasca 2012). Ballast of different shapes and sizes are simulated by connecting and bonding many circular balls at appropriate sizes and positions to resemble the actual aggregates (Fig. 2b). Capping (subballast) and subgrade layers were modelled by the finite difference method (FDM), using the Fast Lagrangian Analysis of Continua, FLAC (Itasca 2010). Interaction between the ballast layer and subgrade was facilitated by a series of interface elements generated at the DEM and FDM boundary. Principally, coupling between DEM and FDM at the ballast-subballast interface can be done by: (i) using the forces acting on the discrete particles as force boundary conditions for the finite difference grids, and (ii) treating the finite difference nodal displacements as velocity boundary conditions for the discrete elements. A mathematical framework to help the coupled model transfer the forces and displacements between the two domains is presented in the following sections. 
173 The Discrete Element Method (DEM) has been often used to model ballast because it can capture 174 the discrete nature of particulate materials (e.g. Oda and Iwashita 1999; O'sullivan 2011). DEM can 175 examine the mechanical behaviour of a granular assembly consisting of a collection of arbitrarily 176 shaped discrete particles subjected to quasi-static and dynamic conditions (Lu and McDowell 2010; 177 O'sullivan and Cui 2009; Tutumluer et al. 2012). In DEM, the force-displacement law derives the 178 contact force acting on two particles in contact to the relative displacement between them (Itasca 179 2012). At a given time, the contact force vector $\overrightarrow{\boldsymbol{F}}$ that represents the interaction between the two 180 particles (Fig. 3) is resolved into normal $\left(\overrightarrow{\boldsymbol{F}}_{N}\right)$ and shear component $\left(\overrightarrow{\boldsymbol{F}}_{T}\right)$ with respect to the contact 181 plane:

$182 \quad \overrightarrow{\boldsymbol{F}}_{N}=K_{N} U^{n}$

$183 \delta \overrightarrow{\boldsymbol{F}}_{T}=-K_{T} \cdot \delta U^{S}$

184 where, $K_{N}$ and $K_{T}$ are the normal and shear stiffnesses at the contact; $U^{n}$ is the normal contact 185 displacement; $\delta U^{S}$ is the incremental shear displacement; and $\delta \overrightarrow{\boldsymbol{F}}_{T}$ is the incremental shear force. 186 The new shear contact force is determined by summing the old shear force existing at the start of 187 the time-step with the shear elastic force increment.

$\overrightarrow{\boldsymbol{F}}_{T} \leftarrow \overrightarrow{\boldsymbol{F}}_{T}+\delta \overrightarrow{\boldsymbol{F}}_{T} \leq \mu \overrightarrow{\boldsymbol{F}}_{N}$

where, $\mu$ is the friction coefficient.

190 The average stress tensor, $\bar{\sigma}_{i j}$ in a given volume $V$ of the ballast assembly is determined by in terms 191 of the summation of discrete contact forces as:

$192 \quad \bar{\sigma}_{i j}=\frac{1}{V} \sum_{N_{c}} \boldsymbol{F}_{j}^{c} x_{i}^{c}$

193 where, $\boldsymbol{F}_{i}^{c}$ and $x_{i}^{c}$ are the contact force and contact vector at contact locations; and $N_{c}$ is the number 194 of contacts in a given volume $V$. These forces include both forces resulting from contact at a point 195 and parallel-bond forces. The contact location, $x_{i}^{c}$ can be rewritten as:

197 where, $x_{i}^{p}$ is the location of the particle centroid; $n_{i}^{c, p}$ is the unit-normal vector directed from the 198 particle centroid to the contact location. 
Substituting Eq. (5) to Eq. (4), and noting that $\sum_{N_{c}} \boldsymbol{F}_{j}^{c}=0$, results in:

$\bar{\sigma}_{i j}=\frac{1}{V} \sum_{N_{c}}\left|x_{i}^{c}-x_{i}^{p}\right| n_{i}^{c, p} \boldsymbol{F}_{j}^{c}$

201 Once the stress tensor, $\bar{\sigma}_{i j}$ is obtained, the vertical and shear stress contours developed across the ballast assembly are plotted and analysed in the following sections.

\section{Finite Difference Model}

204 Subballast and subgrade were modelled using Finite Difference method (FDM) as 100mm thick and $50 \mathrm{~mm}$ thick homogeneous layers (i.e. similar to those in the laboratory), respectively. Given that tracks are symmetrical, the left and right boundaries of the subgrade model were prevented from lateral movement, but allowed to displace vertically. Indeed, the boundaries were considered to be absorbent (viscous) to avoid any spurious reflection of cyclic waves, where the nodes at the bottom boundary were modelled as a pinned supports (i.e. the lateral and vertical displacements were both restrained). The subballast and subgrade were represented with a standard Mohr-Coulomb model

211 (linear elastic-perfectly plastic). In the current analysis, subballast with Young's modulus $E=140$

$212 \mathrm{MPa}$, Poison's ratio $v=0.35$, cohesion $c=3.5 \mathrm{kPa}$, friction angle $\phi=35^{\circ}$, and dilatancy angle $213 \psi=5^{\circ}$; and subgrade with $E=60 \mathrm{MPa}, v=0.33, c=17 \mathrm{kPa}, \phi=14^{0}$, and $\psi=4^{0}$ were 214 selected based on data measured from compression tests and direct shear tests. Initially, a series of walls is generated at the bottom boundary of ballast layer (Zone 1), such that each segment of wall corresponds to a single segment of the surface at the top boundary of the subgrade (Zone 2), as shown in Fig. 2a. Upon cyclic loading, Zone 2 deforms at large strain and the grid-point displacements are then transferred to Zone 1. The resulting wall forces, due to particles interacting with the walls in Zone 1, are transferred to Zone 2 as the grid-point forces are applied via interface elements, as described in the Appendix.

It is noted in the Appendix that only the discrete particles that are in direct contact with the interface elements can exert forces on the interface and the force calculation based on equivalent moment is applied. If an element is moving away from the interface (i.e. discrete particles in the DEM zone), then there are no forces acting on the interface. On the other hand, Equations 1-6 were used to determine the forces and stresses induced for those discrete particles that were located away from the interface. The developed subroutines in the coupled model automatically detect particles that are in contact with the interface and implement the force calculation procedure (i.e. relationship among $d_{1}, d_{2}$ and $L$ with respect to the radius of particle is also determined accordingly). It is also noted that Equation 13 (i.e. determine the distribution of shear along the interface) was only applied for those particles that are in direct contact with the interface. The inertia effect of the element was not 
considered in the current analysis; as the coupled DEM-FDM model was simulated using an approximate quasi-static mode with relatively small time step of $1.9 \times 10^{-5}$ per second, in order to avoid any unduly disturbance to the assembly (Indraratna et al. 2014a, Ngo et al. 2016b).

\section{Modelling the TPSA}

235 A coupled DEM-FDM model of the TPSA apparatus for ballast in a plane strain condition, where 236 the ballast assembly is simulated by a $600 \mathrm{~mm}$ wide and $300 \mathrm{~mm}$ high layer placed over a $150 \mathrm{~mm}$ thick layer of subballast $(100 \mathrm{~mm})$ and subgrade $(50 \mathrm{~mm})$ is illustrated in Fig. 2a. A top wall platen is then forced to move vertically in a sinusoidal waveform to apply the desired cyclic load ( $q_{\max }=$ $420 \mathrm{kPa}$; $q_{\min }=50 \mathrm{kPa}$; frequency, $f=15 \mathrm{~Hz}$ ) while the two vertical walls are moved laterally 240 by a servo controller (Itasca 2012) to maintain a lateral confining pressure of $\sigma_{x x}=10 \mathrm{kPa}$. The 241 simulated ballast particles (Fig. 2b) are placed at random locations within the specified wall 242 boundaries without any overlapping, and then compacted to a bulk unit weight of $15.5 \mathrm{kN} / \mathrm{m}^{3}$ to represent actual laboratory conditions (Indraratna et al. 2013). Micromechanical parameters are chosen by calibrating the shear stress-strain response of ballast obtained from DEM simulations with those measured in the laboratory (Table 1). Cyclic tests at a frequency of $f=15 \mathrm{~Hz}$ are simulated over a number of load cycles, $N=10,000$ where most ballast deformation and degradation occurred, as observed in the laboratory. During loading, displacement of the top plate and two vertical walls were recorded to determine the axial and lateral strains, while stress tensors were computed at specific load cycles to determine the corresponding stress contours.

\section{Results and Discussion}

\section{Load-Deformation Response}

Figure 4a illustrates the applied cyclic stress versus accumulated axial strain obtained from the coupled DEM-FDM model under $N=10,000$ load cycles. It is seen that the predicted axial strains increases remarkably up to around $2 \%$ within the first 1000 load cycles, followed by gradually increasing axial strains up to about $3 \%$ (i.e. within 5,000 cycles), and then remained relatively stable to the end (10,000 cycles). Indeed, the area confined by the cyclic (hysteresis) loops becomes increasingly smaller as the number of cycles increases, indicating that the ballast specimen through cyclic densification begins to respond more elastically with time. The hysteresis loops are also very similar to those obtained in laboratory tests and numerical studies (e.g. Indraratna et al. 2010). The predicted axial and lateral strains are compared with those measured by Indraratna et al. (2013), as shown in Figs. 4b-c. This indicates that the predicted strains agree with the experimental data, and show that most strains occurred after the first 100 cycles, after which permanent deformation decreased considerably. This indicates that the ballast sample experiences considerable 
rearrangement and densification during the initial load cycles. However, after attaining a threshold compression, any subsequent loading would resist further deformation and promote particle crushing (Indraratna et al. 2011). This agrees with the results presented by Lobo-Guerrero and Vallejo (2010) where they stated that ballast deformation increased significantly when particle breakage is included in the analysis. The coupled analysis shows a noticeable discrepancy in the strain curves compared to the experimental data, with a marked increase in strain at $N=5,000-8,000$ load cycles. This difference may be attributed to excessive particle degradation (i.e. contact bond breakage) that could not be captured accurately in the coupled model, as well as the rigid loading plate. Indeed, as the contact bonds broke, it would increase compression on the ballast assembly, followed by a subsequent increase in lateral strain.

\section{Stress Analysis}

The applied stress transmits to the discrete ballast aggregates in the form of contact force-chains where the force-fabric pattern varies with the packing structure, and directly governs the deformation and strength of the discrete (granular) assembly (Oda and Iwashita 1999). Fig. 5 shows the inter-particle forces of the ballast assembly together with vertical stress contours at $N=10,1000$, and $N=5000$ cycles. Each contact force is represented at the contact point by a 'black line' oriented in the direction of the force and with a thickness proportional to its intensity. Here, most of the contact forces plot in a vertical direction, but upon repeated loading, large contact forces concentrate beneath the loading plate and around edges of the wall, while a significant part of the applied load is still being transmitted vertically to the underlying subballast and subgrade (Figs. 5bc). Moreover, the force distributed in the DEM region is always heterogeneous, where the maximum contact forces change with the load cycles, and compressive stress $\left(\sigma_{y y}\right)$ in the subgrade is greater around the interface area that is in direct contact with the aggregates, and as expected, it decreases with depth.

Fig. 6 presents the vertical $\left(\sigma_{y y}\right)$ and shear $\left(\sigma_{x y}\right)$ stress contours in the ballast assembly that are subjected to a maximum cyclic load at $N=100$ and 1000. The stresses induced in the ballast assembly are determined by the contact forces acting on it (Equation 6). Note that the stresses are distributed non-uniformly across the assembly (i.e. for both $\sigma_{y y}$ and $\sigma_{x y}$ ) and decrease with depth, although maximum stresses tend to occur beneath the loading plate and the edges of the wall, which is consistent with the contact force distributions described above. Locally, the vertical stress $\sigma_{y y}$ has a maximum value of about $410 \mathrm{kPa}$, while the peak shear stress, $\sigma_{x y}$ is around $100 \mathrm{kPa}$. It is noted that loads (i.e. vertical and shear stresses) applied on the top surface of ballast assemblies are transmitted to ballast grains through an interconnected network of force chains at contact points (Fig. 5). These forces create the deformation of the assembly (i.e. vertical and lateral displacements) 
and the breakage of contact bonds (i.e. particle breakage). The stresses at the bottom of ballast assembly, therefore, are much lower than those measured at the top surface (gravitational force is 300 considered in the DEM analysis). It is also noted that the applied loads are diminished with depth and the influence of rigid boundary walls leading to unbalance forces the top and the bottom of the ballast.

\section{Particle Breakage and the Effect of Subgrade Stiffness}

In this current analysis the degradation of contact bonds within a cluster of particles represents particle breakage. The effect the loading frequency has on the deformation of a ballast assembly was investigated by conducting a DEM-FDM analysis at varying frequencies. Fig. 7a shows the predicted evolution of bond breakage at various cyclic loadings subjected to different load frequencies $f=15 \mathrm{~Hz}$ to $30 \mathrm{~Hz}$. The ballast breakage index (BBI) measured in the laboratory is also plotted for a comparison. Here, the evolution of broken bonds is similar to the changes of BBI observed in the laboratory where bond breakage generally increases as the load frequency increases. The predicted bond breakage increased rapidly and attained a relatively stable value after about 5,000 cycles. The amount of broken bonds in the range of $100 \leq N \leq 5,000$ increased markedly with only a marginal increase in bond breakage in the subsequent loading. In comparison to 15-25 $\mathrm{Hz}$, the predicted amount of broken still increased slightly, even after 8,000 cycles for $f=30 \mathrm{~Hz}$, thus demonstrating continuing cyclic densification at high frequencies. Figs. 7b-d illustrate the number and location of bond breakages at different stages of cyclic loading, varying from 500 to 10,000 cycles under a frequency of $f=15 \mathrm{~Hz}$. For $N<1,000$ cycles, most bonds break just below the loading plate due to induced high contact forces (Fig. 7b), so it is obvious that an increase in the cyclic load will result in more bond breakage (Figs. 7c, 7d), and a re-arrangement of broken particles (i.e. densification) will lead to a denser and more uniform distribution of contact force, as shown earlier in Fig. 5.

The influence of subgrade stiffness on the deformation of the ballast assembly (excluding subgrade deformation) was studied where the subgrade varied in stiffness from $15 \mathrm{MPa}$ for soft subgrade to $100 \mathrm{MPa}$ for relatively stiff subgrade at $f=15 \mathrm{~Hz}$. Fig. 8 presents the evolutions of axial strains and the amount of broken bonds for different subgrade moduli. With weak subgrade (e.g. $E=15$ $\mathrm{MPa}$ ) the ballast assembly exhibits the highest axial strain (Fig. 8a) while sustaining the lowest amount of broken bonds (Fig. 8b), unlike the stiffer subgrade. Indeed, weak subgrade could act like an energy absorbing layer that attenuates the transmission of impact induced cyclic loads and substantially reduces ballast breakage. 


\section{Application to a Case Study}

331 A DEM-FDM analysis was carried out to predict the load-deformation response of actual tracks in 332 the town of Singleton (located about $200 \mathrm{~km}$ from Sydney, NSW, Australia). Field data measured 333 by Indraratna et al. (2014b) were used to compare with the current numerical analysis. A field trial 334 was carried out along a section of instrumented track where two types of subgrade, i.e. relatively 335 soft general fill and hard rock (i.e. Section A and Section C, respectively) were examined. The track 336 substructure consisted of a $300 \mathrm{~mm}$ thick layer of ballast placed over $150 \mathrm{~mm}$ thick capping layer, 337 overlying structural fill (thickness varying from 500 to $900 \mathrm{~mm}$ ).

338 The combined DEM-FDM model used to simulate the settlement $S_{v}$ of the half- track is shown in 339 Fig. 9a, where the contact force chains and vertical stress contours were captured at $N=10,000$. 340 Note that the geometry, boundary conditions, and applied cyclic loads were modelled like those 341 carried out in the field (i.e. mean cyclic stress of $235 \mathrm{kPa}$; frequency of $15 \mathrm{~Hz}$ ) to realistically 342 represent simulated freight trains with axle loads of $25-30$ tonnes travelling at $80 \mathrm{~km} / \mathrm{h}$. The 343 simulation shows that ballast directly underneath the sleeper experiences denser contact forces than 344 ballast at the shoulder of the embankment, and this causes vertical stress $\left(\sigma_{y y}\right)$ at the interface 345 between the ballast and capping to be distributed non-uniformly along the interface, where 346 increased stresses occur towards the centre of track; this supports the data measured in the field by 347 Indraratna et al. (2014b).

348 Comparisons of the settlement $S_{v}$ of ballast for two types of subgrades obtained from the numerical 349 model and field measurements are presented in Fig. 9b, where settlement was measured beneath the 350 sleeper. It is evident that the model predicts the vertical deformation of ballast well in relation to the 351 observed field data using settlement pegs, where only a slight deviation from those measurements 352 was found. Where $N=10,000$, the measured value of $S_{v}$ for hard subgrade of $6.07 \mathrm{~mm}$ compares 353 well with the predicted value of $6.71 \mathrm{~mm}$. The notable increase in settlement predicted for soft 354 subgrade $\left(S_{v}=10.21 \mathrm{~mm}\right)$ compared to the field observation of $S_{v}=8.72 \mathrm{~mm}$ can be attributed to 355 inevitable discrepancies between the field conditions and the computational model that adopted 356 plane strain conditions.

\section{Conclusion}

358 Large scale simulation testing of the track process was carried out to study the load-deformation of 359 ballast subjected to cyclic loading. Laboratory results showed that ballast experienced a significant 360 axial strain during the initial load cycles, followed by a gradually increasing settlement that became 361 relatively stable towards the end. A coupled DEM-FDM model was introduced to study the load362 deformation responses of ballast in a plane strain, where the aggregates were modelled by the 
363 discrete element method and the subgrade (continuum) by the finite difference method. The two 364 domains, DEM and FDM interacted with each other via interface elements, where DEM transferred 365 the forces as an input to FDM, which then updated the displacements back to DEM using 366 mathematical subroutines.

367 The computed values of axial and lateral strains compared to the experimental data, indicated that 368 the coupled DEM-FDM model proposed here could capture the correct load-displacement 369 behaviour under cyclic loading $(N=100-10,000)$. The model indicated that the extent of bond 370 breakage in the ballast assembly increased with the frequency $(f=15-30 \mathrm{~Hz})$. The contact force 371 distributions and stress contours induced in the ballast at varying stages of cyclic loading were 372 analysed, and confirmed that the stresses would transfer non-uniformly across the ballast assembly 373 such that maximum stress would occur beneath the sleeper corresponding to greatest number of 374 broken bonds. The influence of subgrade stiffness on axial strain and bond breakage was also 375 analysed, and it showed that an increase in the subgrade stiffness resulted in an increased number of 376 broken bonds. The DEM-FDM analysis was also used to predict the load-deformation response of 377 an instrumented track in Singleton. The predicted settlement was comparable to the measured field 378 data indicating that the proposed DEM-FDM model is reliable. 
382 Interface elements were created at the boundary of ballast and subgrade to help implement the 383 coupling process where conditions of equilibrium and compatibility must be satisfied at the 384 interface. Assuming an interface element (segment) is defined by end-point locations, $X_{1}, X_{2}$; a 385 length, $L$ and a particle contact force, $\boldsymbol{F}_{i}^{c}=\boldsymbol{F}_{\mathbf{1}}+\boldsymbol{F}_{\mathbf{2}}$, act at the particle centroid, $X_{p}$, as shown in 386 Fig. 10. The contact forces acting at the segment end points, $\boldsymbol{F}_{\mathbf{1}}$, and $\boldsymbol{F}_{\mathbf{2}}$ can be described in terms 387 of shear and normal component vectors with corresponding unit vectors, $\hat{t}$ and $\hat{n}$ :

$388 \quad \boldsymbol{F}_{\mathbf{1}}=F_{1_{X}} \hat{t}+F_{1_{Y}} \hat{n}$

$\boldsymbol{F}_{2}=F_{2_{X}} \hat{t}+F_{2_{Y}} \hat{n}$

390 The force components $F_{1_{X}}, F_{1_{Y}}, F_{2_{X}}$, and $F_{2_{Y}}$ were determined by satisfying a condition whereby

391 the force acting at the segment end points should produce the same moment about $X_{1}$ as the particle 392 contact force:

$d_{1} \times \boldsymbol{F}_{i}^{c}=L \hat{t} \times \boldsymbol{F}_{2}=L \hat{t} \times\left(F_{2_{X}} \hat{t}+F_{2_{Y}} \hat{n}\right)$

$d_{1} \times F_{i}^{c}=L F_{2_{X}}(\hat{t} \times \hat{t})+L F_{2_{Y}}(\hat{t} \times \hat{n})$

or, $\left(d_{1 x} \hat{t}+d_{1 y} \hat{n}\right) \times\left(F_{x} \hat{t}+F_{y} \hat{n}\right)=L F_{2_{Y}}(\hat{t} \times \hat{n})$

given that: $\hat{t} \times \hat{t}=0 ; \hat{n} \times \hat{n}=0$; and $\hat{t} \times \hat{n}=\hat{k}$

thus, $\left(d_{1 x} F_{y}-d_{1 y} F_{x}\right) \hat{k}=L F_{2_{Y}} \hat{k}$, or

$F_{2_{Y}}=\frac{\left(d_{1 x} F_{y}-d_{1 y} F_{x}\right)}{L}$

Distributing the shear components based on the nearest of $X_{p}$ to each end point to obtain $F_{1_{X}}$, as given:

$$
F_{1_{X}}=\left(\frac{\left|d_{2}\right|}{\left|d_{1}\right|+\left|d_{2}\right|}\right)\left(\boldsymbol{F}_{i}^{c} \cdot \hat{t}\right)
$$

402 The forces acting at the segment end points should produce the same total force as the particle

403 reaction force: $\boldsymbol{F}_{i}^{c}=\boldsymbol{F}_{\mathbf{1}}+\boldsymbol{F}_{\mathbf{2}}$

404 Expressing Eq. (14) in terms of the unit-tangent vector, which gives two equations:

$$
\boldsymbol{F}_{\boldsymbol{x}}=\left(F_{1_{X}}+F_{2_{X}}\right) t_{x}-\left(F_{1_{Y}}+F_{2_{Y}}\right) t_{y}
$$


407 Rearranging Eqs. (15) and (16), results in:

$F_{1_{Y}}=\left[\left(\boldsymbol{F}_{\boldsymbol{y}}-F_{2_{Y}} t_{x}-F_{1_{X}} t_{y}\right) t_{x}+\left(-\boldsymbol{F}_{\boldsymbol{x}}-F_{2_{Y}} t_{y}+F_{1_{X}} t_{x}\right) t_{y}\right] / 2$

$409 \quad F_{2_{X}}=\left\{\begin{array}{l}\frac{F_{x}+\left(F_{1_{Y}}+F_{2_{Y}}\right) t_{y}-F_{1_{X}} t_{x}}{t_{x}}, \text { or } \\ \frac{\boldsymbol{F}_{\boldsymbol{y}}-\left(F_{1_{Y}}+F_{2_{Y}}\right) t_{x}-F_{1_{X}} t_{y}}{t_{y}}\end{array}\right.$

410 When the above equations are applied the segment forces acting in Zone $2\left(F_{1_{X}}, F_{1_{Y}}, F_{2_{X}}\right.$, and $\left.F_{2_{Y}}\right)$ 411 should produce the same total force and moment as the particle contact forces acting on Zone 1 at 412 the interface (Fig. 2a), so both zones along the interface boundary experience the same loading 413 condition. Subroutines written in FISH language were developed by the Authors so that all the 414 aforementioned equations could be used to implement a fully coupled DEM-FDM analysis.

\section{Acknowledgements}

418 The authors are grateful to Professor Glenn McDowell who provided valuable discussions and 419 comments during the preparation of the paper. The authors are grateful for the financial support 420 provided by the Australian Research Council (ARC). Laboratory assistance from technicians, Alan 421 Grant and Ian Bridge during the laboratory tests is also very much appreciated. 


\section{Notation}

424 The following symbols are used in this paper:

$425 \quad B B I=$ ballast breakage index;

$426 \quad c=$ cohesion;

$427 d_{1,2}=$ distances from particle centroid to the segment end points;

$428 d_{50}=$ medium value of the particle size distribution;

$429 E$ = Young's modulus;

$430 f=$ cyclic frequency;

$431 \quad \overrightarrow{\boldsymbol{F}}=$ contact force;

$432 \quad \overrightarrow{\boldsymbol{F}}_{N}=$ contact normal force;

$433 \quad \overrightarrow{\boldsymbol{F}}_{T}=$ contact shear force;

$434 \boldsymbol{F}_{i}^{c}=$ contact force at contact location, $x_{i}^{c}$;

$435 \boldsymbol{F}_{\mathbf{1}, \mathbf{2}}=$ contact forces acting at the segment end points;

$436 F_{1_{X}}, F_{1_{Y}}, F_{2_{X}}$, and $F_{2_{Y}}=$ force components in horizontal and vertical directions;

$437 \delta \overrightarrow{\boldsymbol{F}}_{T}=$ incremental shear force;

$438 \quad K_{N}=$ contact normal stiffness;

$439 K_{T}=$ contact shear stiffness;

$440 \hat{k}=$ binormal vector to tangent and normal;

$441 \quad L=$ length of element

$442 N=$ number of load cycles;

$443 \quad N_{c}=$ number of contacts;

$444 n_{i}^{c, p}=$ unit-normal vector directed from the particle centroid to the contact location;

$445 \hat{n}=$ unit normal vector;

$446 \quad q_{\max }=$ maximum cyclic stress;

$447 \quad q_{\min }=$ minimum cyclic stress;

$448 S_{v}=$ vertical settlement;

$449 \quad x_{i}^{c}=$ contact location;

$450 \quad x_{i}^{p}=$ location of the particle centroid;

$451 \hat{t}=$ unit tangent vector;

$452 U^{n}=$ normal contact displacement;

$453 \delta U^{S}=$ incremental shear displacement;

$454 \mu=$ friction coefficient;

$455 \quad v=$ Poison's ratio;

$456 \quad \varepsilon_{x}=$ lateral strain; 
$457 \quad \varepsilon_{y}=$ vertical strain;

$458 \phi=$ friction angle;

$459 \psi=$ dilatancy angle

$460 \quad \sigma_{x x}=$ horizontal stress;

$461 \quad \sigma_{y y}=$ vertical stress;

$462 \sigma_{x y}=$ shear stress; and

$463 \bar{\sigma}_{i j}=$ stress tensor.

464 


\section{References}

466

Australian Standard: AS 2758.7 (1996). Aggregates and rock for engineering purposes; Part 7: Railway ballast, Sydney, NSW, Australia.

Anderson, W. F. , and Fair, P. (2008). "Behavior of railroad ballast under monotonic and cyclic loading." Journal of Geotechnical and Geoenvironmental Engineering, 143(3), 316-327.

Bhandari, A. , and Han, J. (2010). "Investigation of geotextile-soil interaction under a cyclic vertical load using the discrete element method". Geotextiles and Geomembranes, 28(1), 33-43.

Cui, L. , and O'Sullivan, C. (2006). "Exploring the macro- and micro-scale response of an idealised granular material in the direct shear apparatus". Géotechnique, 56(7), 455-468.

Cundall, P. A. , and Strack, O. D. L. (1979). "A discrete numerical model for granular assemblies". Géotechnique, 29(1), 47-65.

Esveld, C. (2001). Modern railway track, MRT Press, The Netherlands.

Itasca (2010). FLAC - Fast Lagrangian Analysis of Continua, Version 6.0, Itasca Consulting Group, Minneapolis, MN.

Itasca. (2012). Particle flow code in two and three dimensions, Itasca Consulting Group, Inc., Minnesota.

Indraratna, B. , and Salim, W. (2005). Mechanics of ballasted rail tracks - A Geotechnical Perspective, Taylor and Francis, Balkema, London, UK.

Lackenby, J., Indraratna, B., McDowell, G. R. , and Christie, D. (2007). "Effect of confining pressure on ballast degradation and deformation under cyclic triaxial loading." Géotechnique, 57(6), 527-536.

Indraratna, B., Thakur, P. K. , and Vinod, J. S. (2010). "Experimental and numerical study of railway ballast behavior under cyclic loading." International Journal of Geomechanics, ASCE, 10(4), 136-144.

Indraratna, B., Salim, W. , and Rujikiatkamjorn, C. (2011a). Advanced Rail Geotechnology Ballasted Track, CRC Press, Taylor \& Francis Group, London, UK.

Indraratna, B., Ngo, N.T. , and Rujikiatkamjorn, C. (2011b). "Behavior of geogrid-reinforced ballast under various levels of fouling." Geotextiles and Geomembranes, 29(3), 313-322.

Indraratna, B., Ngo, N.T. , and Rujikiatkamjorn, C. (2013). "Studying the deformation of coal fouled ballast stabilised with geogrid under cyclic load". Journal of Geotechnical and Geoenvironmental Engineering-ASCE, 139(8), 1275-1289.

Indraratna, B. , and Nimbalkar, S. (2013). "Stress-strain degradation response of railway ballast stabilized with geosynthetics." Journal of Geotechnical and Geoenvironmental Engineering, ASCE, 139(5), 684-700. 
Indraratna, B., Ngo, N.T, Rujikiatkamjorn, C. , and Vinod, J. (2014a). "Behaviour of fresh and fouled railway ballast subjected to direct shear testing - a discrete element simulation." International Journal of Geomechanics, ASCE, 14(1), 34-44.

Indraratna, B., Nimbalkar, S. , and Rujikiatkamjorn, C. (2014b). "From theory to practice in track geomechanics - Australian perspective for synthetics inclusions." Transportation Geotechnics, 1(2014), 171-187.

Lobo-Guerrero, S. , and Vallejo, L. E. (2006). "Discrete element method analysis of railtrack ballast degradation during cyclic loading." Granular Matter,. 8(3-4), 195-204.

Lobo-Guerrero, S. , and Vallejo, L. E. (2010). "Crushing of particles under simulated static and centrifuge forces." GeoFlorida 2010: Advances in Analysis, Modeling \& Design (Geotechnical Special Publication, 199), ASCE, 550-559.

Lu, M. , and McDowell, G. R. (2010). "Discrete element modelling of railway ballast under monotonic and cyclic triaxial loading." Géotechnique, 60(6), 459-467.

Huang, H. , and Tutumluer, E. (2011). "Discrete element modeling for fouled railroad ballast." Construction and Building Materials, 25, 3306-3312.

McDowell, G. R. , and Harireche, O. (2002). "Discrete element modelling of soil particle fracture." Géotechnique, 52(2), 131-135.

McDowell, G. R., Harireche, O., Konietzky, H., Brown, S. F. , and Thom, N. H. (2006). "Discrete element modelling of geogrid-reinforced aggregates." Proceedings of the ICE - Geotechnical Engineering, 159(1), 35-48.

Ngo, N.T., Indraratna, B. , and Rujikiatkamjorn, C. (2014). "DEM simulation of the behaviour of geogrid stabilised ballast fouled with coal." Computers and Geotechnics, 55, 224-231.

Ngo, N.T., Indraratna, B., Rujikiatkamjorn, C. , and Biabani, M. (2016a). "Experimental and discrete element modeling of geocell-stabilized subballast subjected to cyclic loading". Journal of Geotechnical and Geoenvironmental Engineering-ASCE, 142(4), 04015100,1-14.

Ngo, N.T, Indraratna, B., and Rujikiatkamjorn, C. (2016b). "Micromechanics-based investigation of fouled ballast using large-scale triaxial tests and discrete element modeling”. Journal of Geotechnical and Geoenvironmental Engineering-ASCE, DOI: 10.1061/(ASCE)GT.19435606.0001587, pp:04016089, 1-16.

O'Sullivan, C. (2011). Particulate Discrete Element Modelling: A Geomechanics Perspective, Spon press, London.

O'Sullivan, C. , and Cui, L. (2009). "Micromechanics of granular material response during load reversals: Combined DEM and experimental study." Powder Technology, 193, 289-302.

Oda, M. , and Iwashita, K. (1999). Mechanics of granular materials: An introduction, Rotterdam: A. A. Balkema. 
534 Selig, E. T. , and Waters, J. M. (1994). Track geotechnology and substructure management, 535 Thomas Telford, London.

536 Suiker, A. S. J. , and Borst, R. (2003). "A numerical model for the cyclic deterioration of railway 537 tracks." International Journal for Numerical methods in Engineering, 57, 441-470.

538 Suiker, A. S. J., Selig, E. T. , and Frenkel, R. (2005). "Static and cyclic triaxial testing of ballast and 539 subballast." Journal of Geotechnical and Geoenvironmental Engineering, ASCE, 131(6), 771$540 \quad 782$.

541 Tutumluer, E., Huang, H. , and Bian, X. (2012). "Geogrid-aggregate interlock mechanism 542 investigated through aggregate imaging-based discrete element modeling approach." 543 International Journal of Geomechanics, ASCE, 12(4), 391-398. 
547 Table 1. Micro-mechanical parameters of ballast particles and walls applied in DEM simulation 548

\begin{tabular}{l|l}
\hline Micro-mechanical parameters & Values \\
\hline Radius of particle $(\mathrm{m})$ & $1.8 \times 10^{-3}-16 \times 10^{-3}$ \\
Inter-particle coefficient of friction & 0.80 \\
Particle normal and shear contact stiffness $(\mathrm{N} / \mathrm{m})$ & $3.58 \times 10^{8}$ \\
Normal and shear stiffness of wall $(\mathrm{N} / \mathrm{m})$ & $3 \times 10^{7}$ \\
Parallel bond normal and shear stiffness $(\mathrm{N} / \mathrm{m})$ & $6.25 \times 10^{10}$ \\
Parallel bond normal and shear strength $\left(\mathrm{N} / \mathrm{m}^{2}\right)$ & $5.78 \times 10^{6}$ \\
Parallel bond radius multiplier & 0.5 \\
Particle unit weight $\left(\mathrm{kN} / \mathrm{m}^{3}\right)$ & 15.5 \\
\hline
\end{tabular}



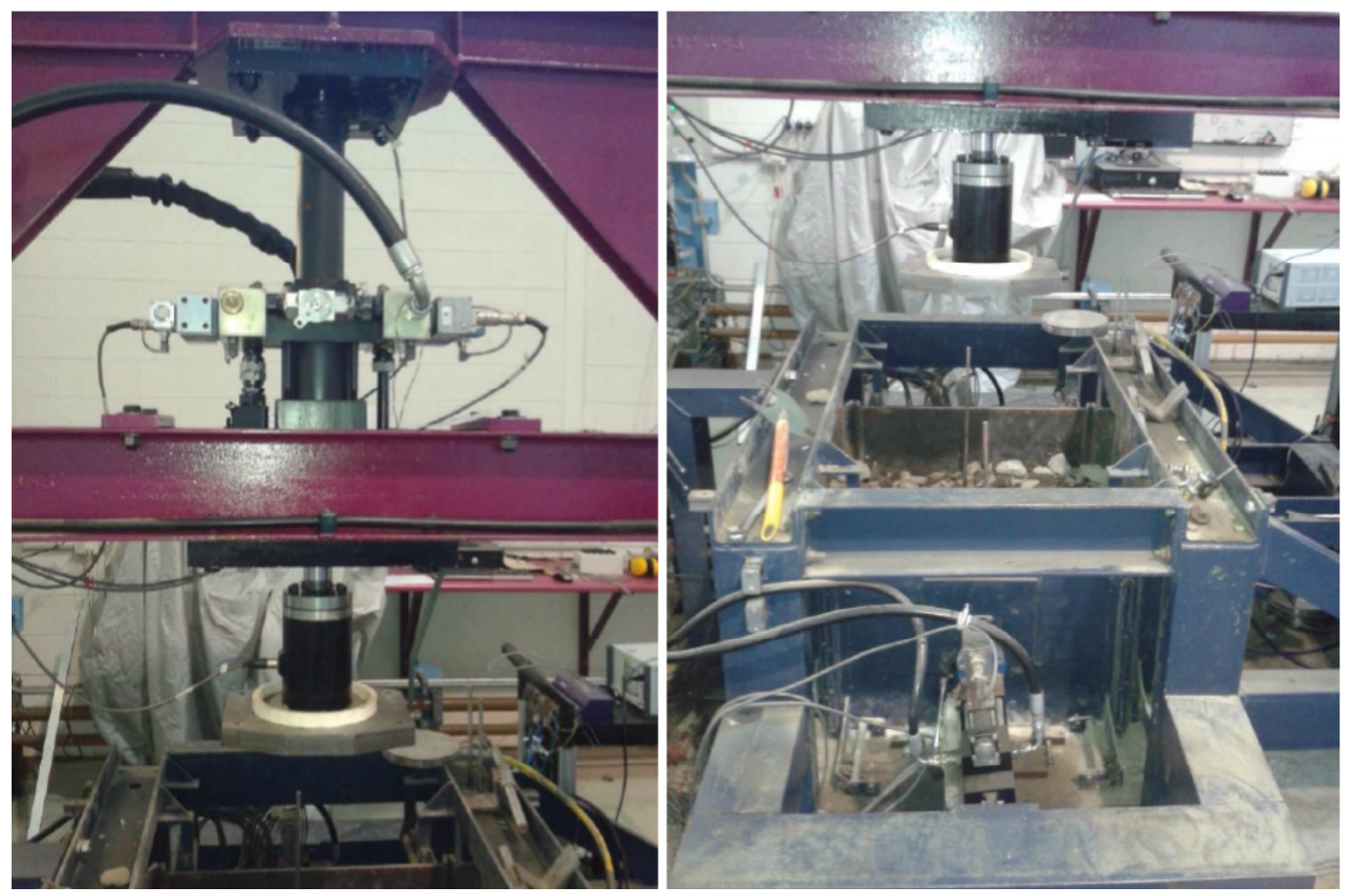

(a)

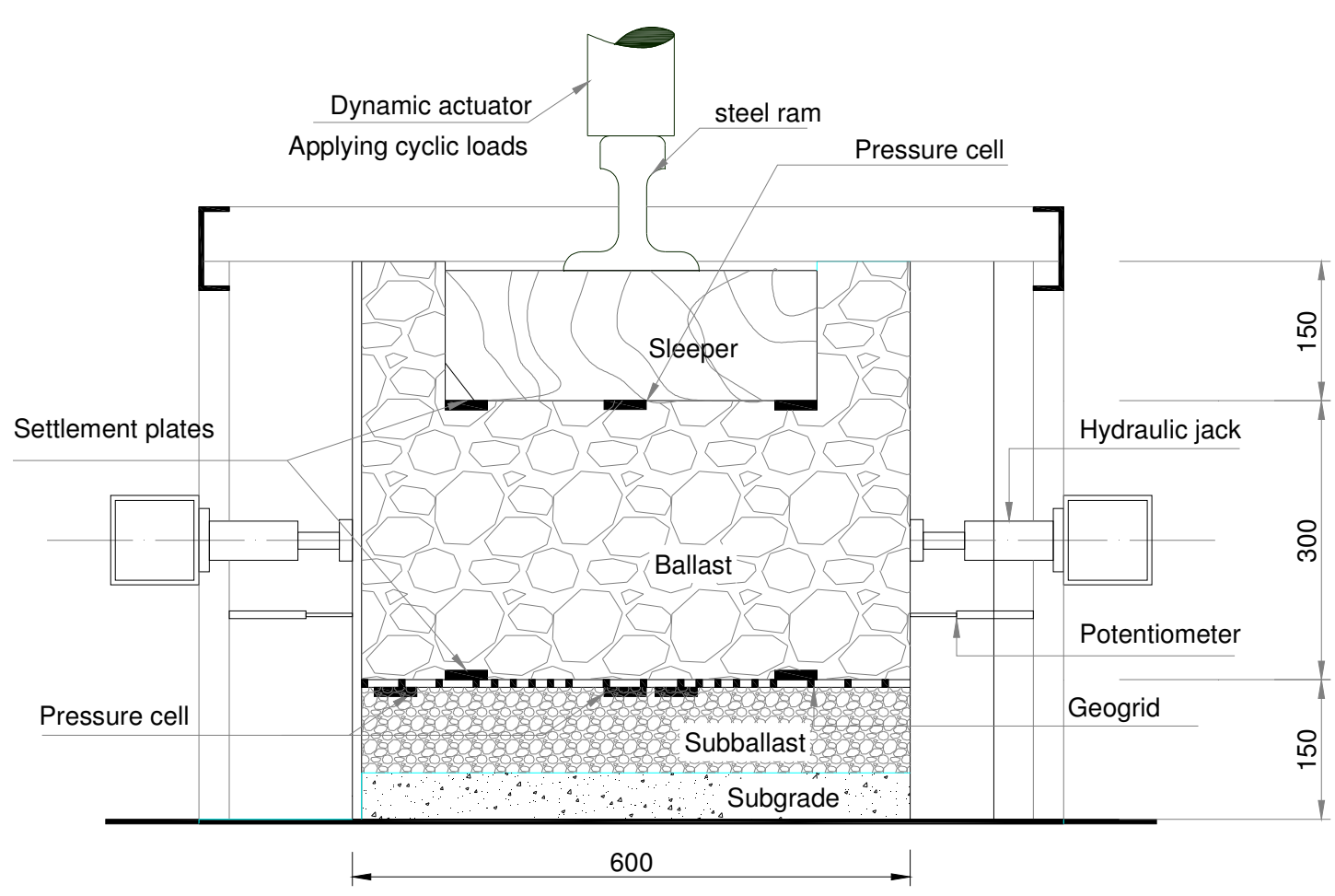

(b)

553 Fig. 1. Track Process Simulation Apparatus, TPSA : (a) perspective views of the apparatus; (b) 554 cross-section of the TPSA. 

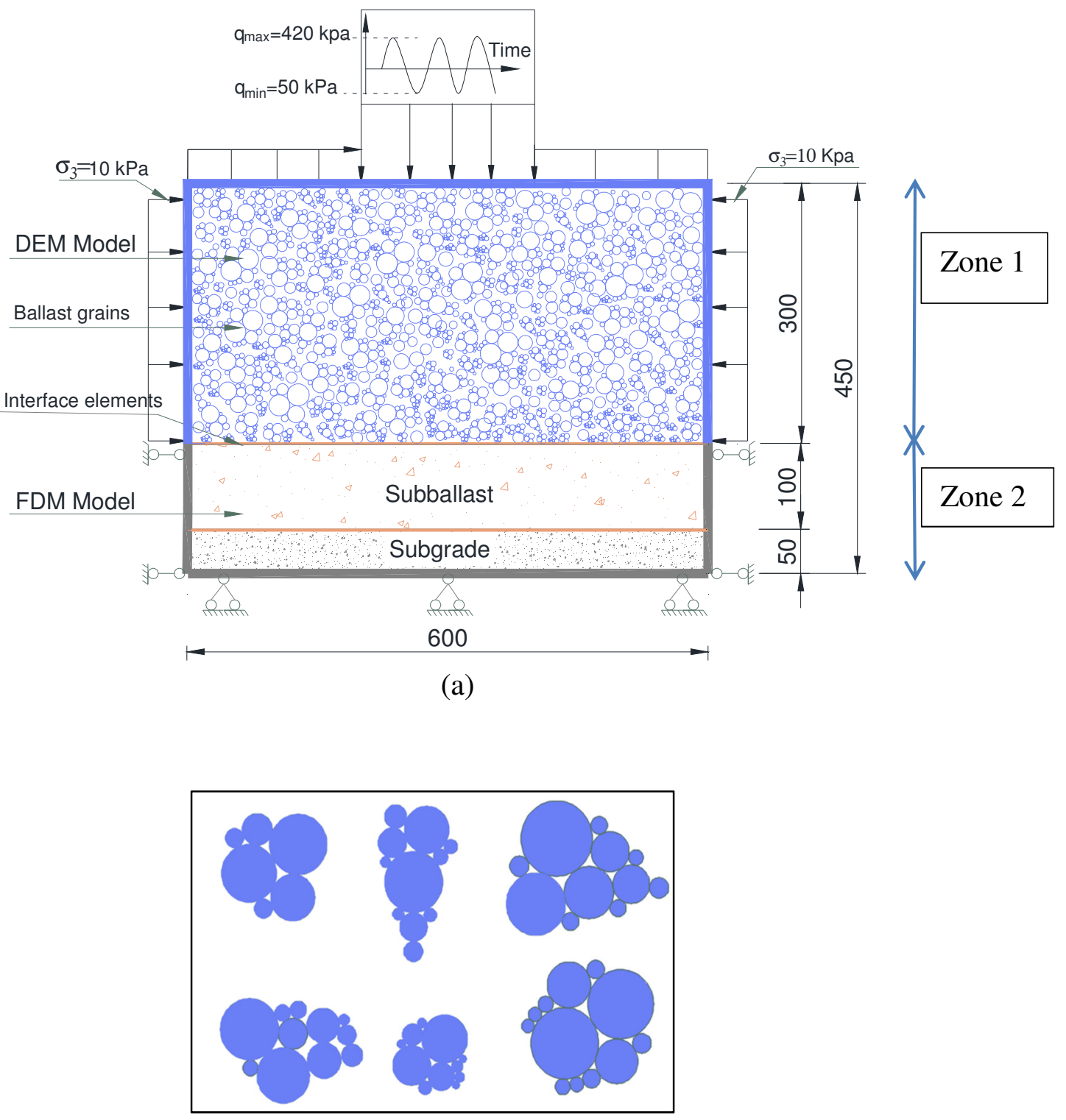

(b)

560 Fig. 2. (a) Schematic diagram of a coupled DEM-FDM to model TPSA for ballast (dimensions are 561 in $\mathrm{mm}$ ); (b) Irregular-shaped particles 


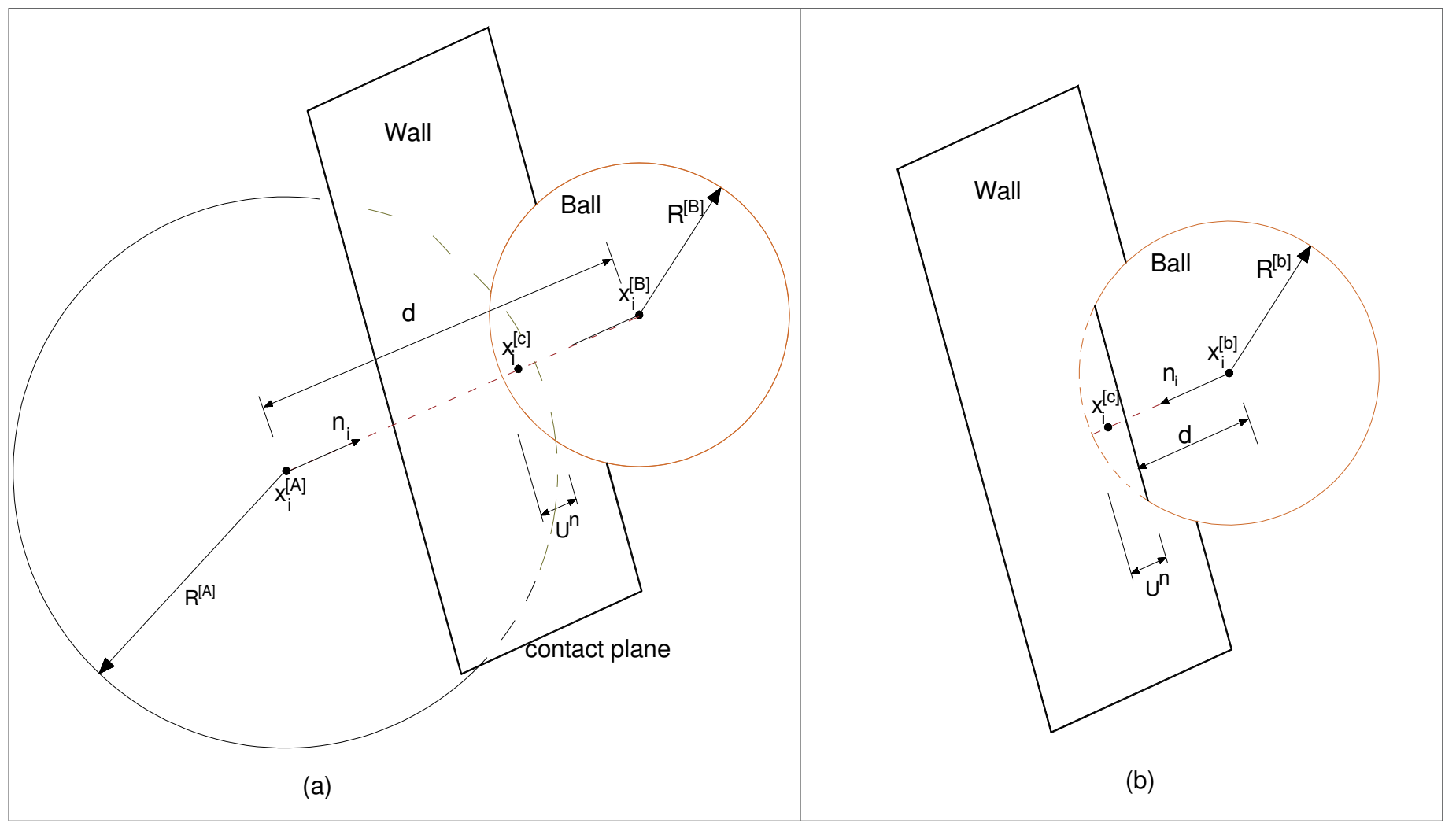

Fig. 3. Notations used to describe contacts in DEM: (a) ball-ball contact; (b) ball-wall contact 

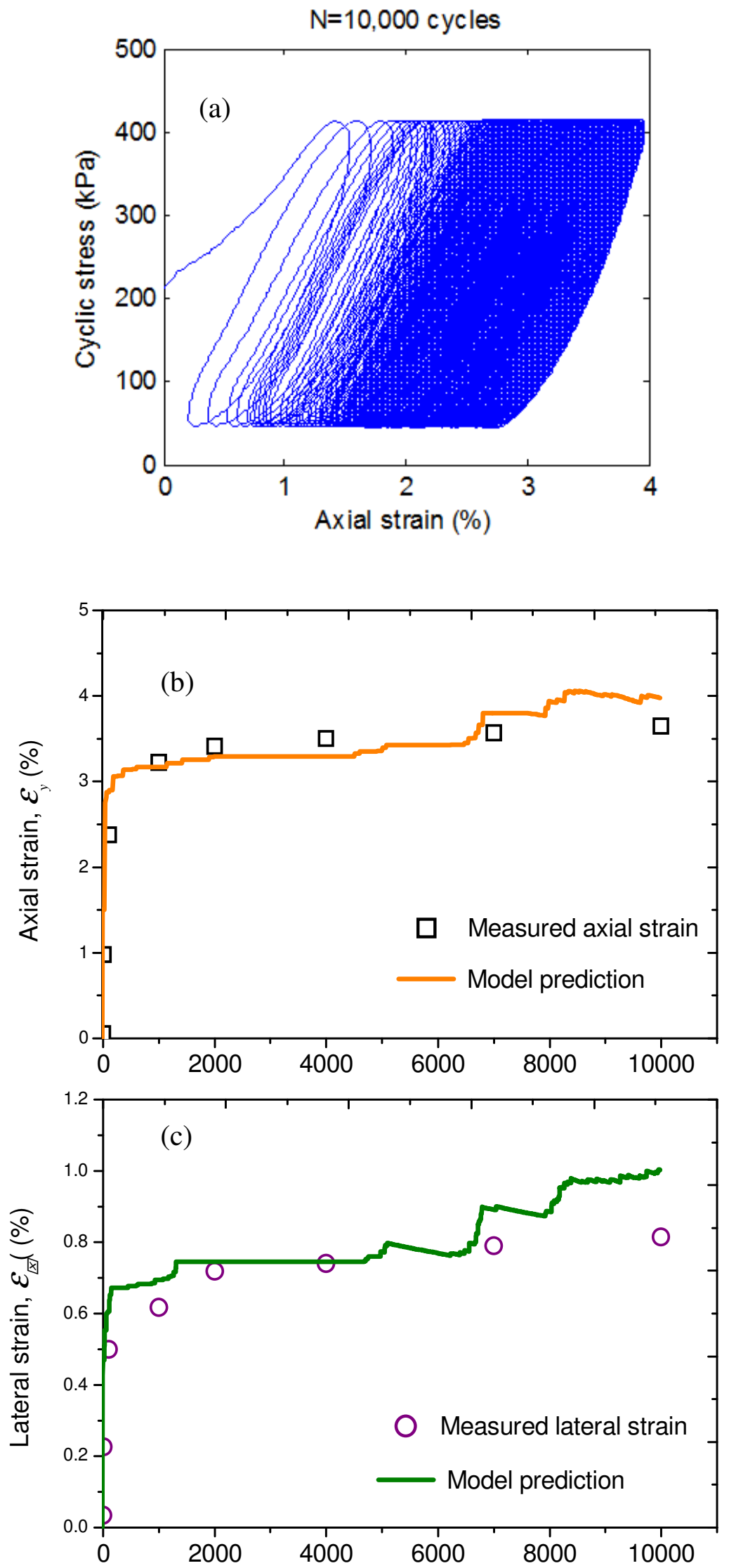

Number of cyclic cycles, $\mathrm{N}$

566 Fig. 4. (a) applied cyclic stress versus axial strain; (b) axial strain versus number of load cycles; (c) lateral strains versus number of load cycles 


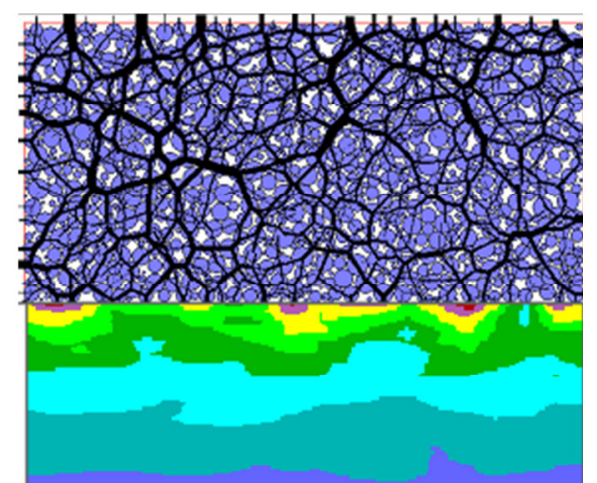

Number of contact: 1571

Maximum contact force: 491 (N)

(a)

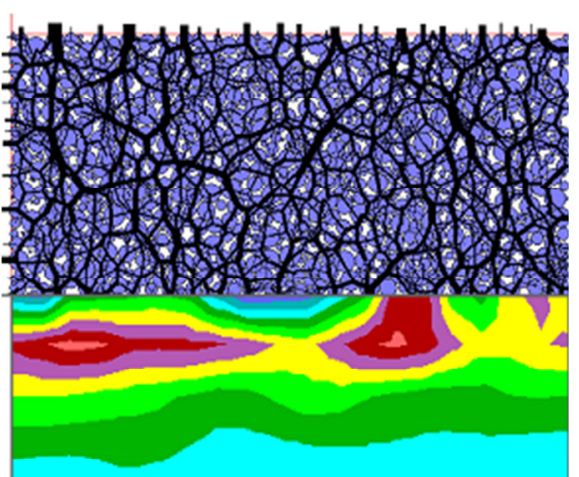

Number of contact: 1746

Maximum contact force: $782(\mathrm{~N})$

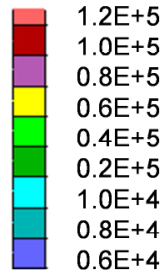

(b)

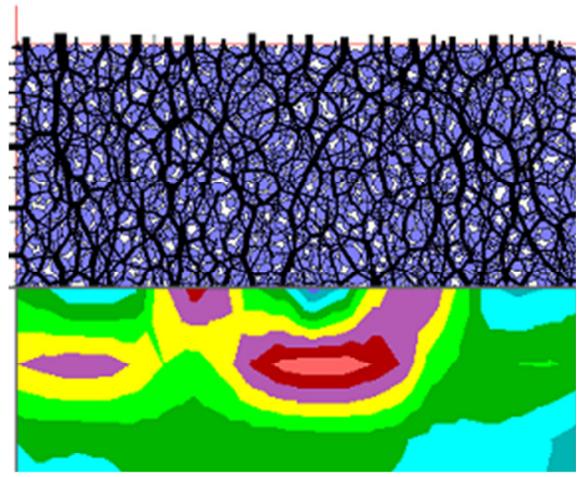

Number of contact: 1895
Maximum contact force:
$973(\mathrm{~N})$

(c)

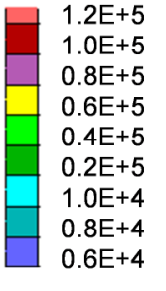

Fig. 5. Vertical stress contour $\left(\sigma_{y y}\right)$ in FDM region and contact force distribution in DEM region at 572 different load cycles; (a) 10 cycles; (b) 1000 cycle; and (c) 5000 cycles; (contour unit in Pascal) 

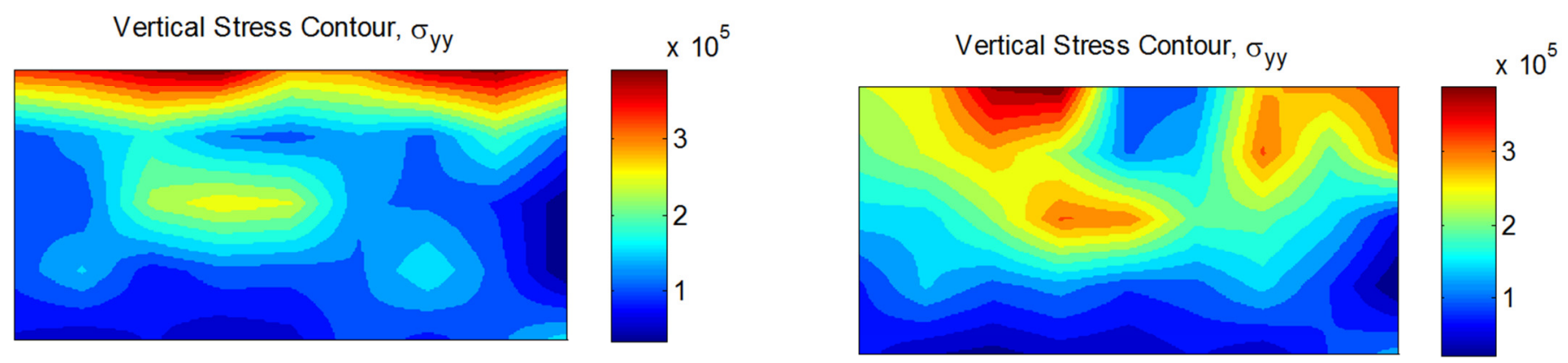

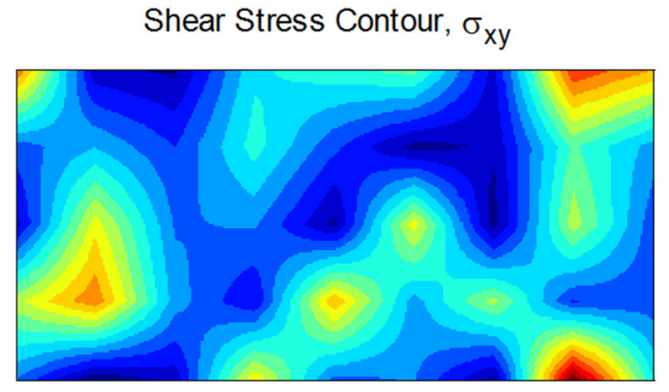

(a)

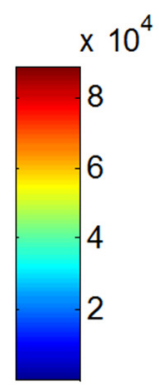

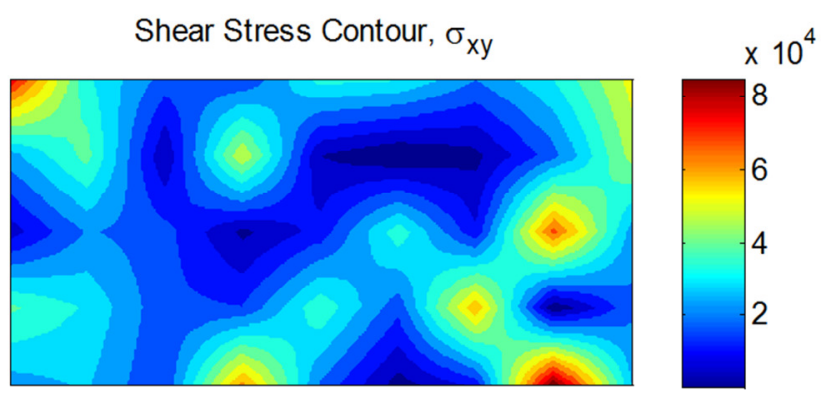

(b)

575 Fig. 6. Vertical and shear stress contours developed in the ballast assembly at different load cycles; 576 (a) 100 cycles; (b) 1000 cycles; (contour unit in Pascal) 


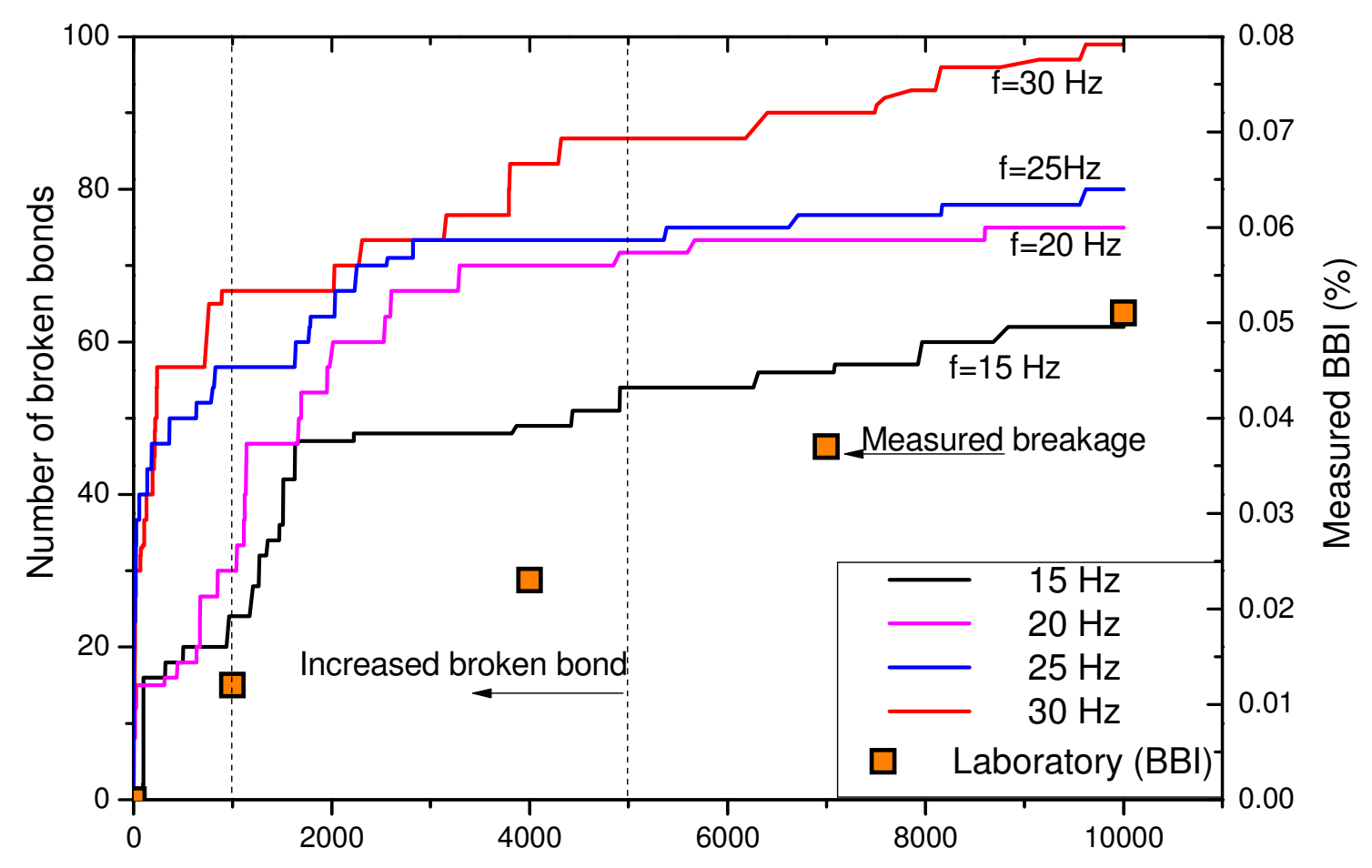

Number of cycles, $\boldsymbol{N}$

(a)

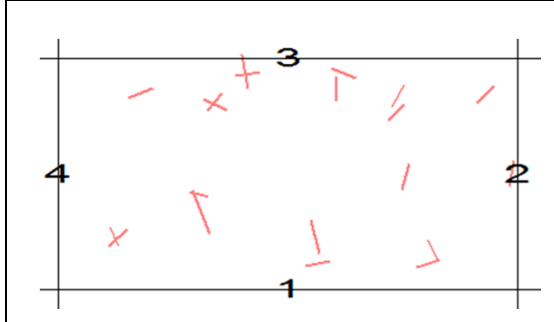

(b) Load cycle, $N=500$ Number of broken bonds $=20$

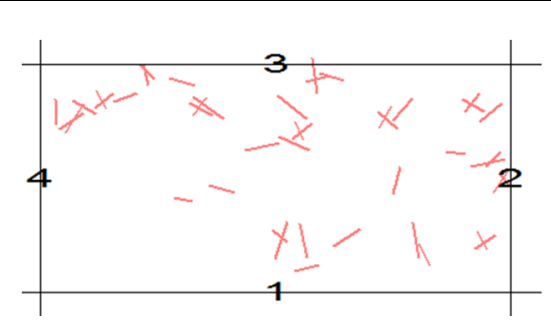

(c) Load cycle, $N=5,000$ Number of broken bonds $=54$

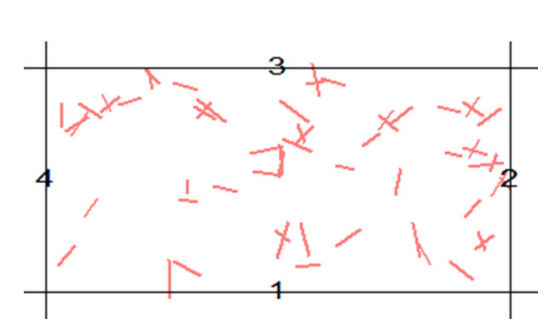

(d) Load cycle, $N=10,000$ Number of broken bonds $=62$

580 Fig. 7. (a) Comparison of the number of simulated broken bonds with actual ballast breakage index 581 (BBI) from laboratory testing; (b)-(d): Snapshots of bond breakage at varying load cycles: (b) $N=500 ;$ (c) $N=5,000 ;$ (d) $\mathrm{N}=10,000$ 

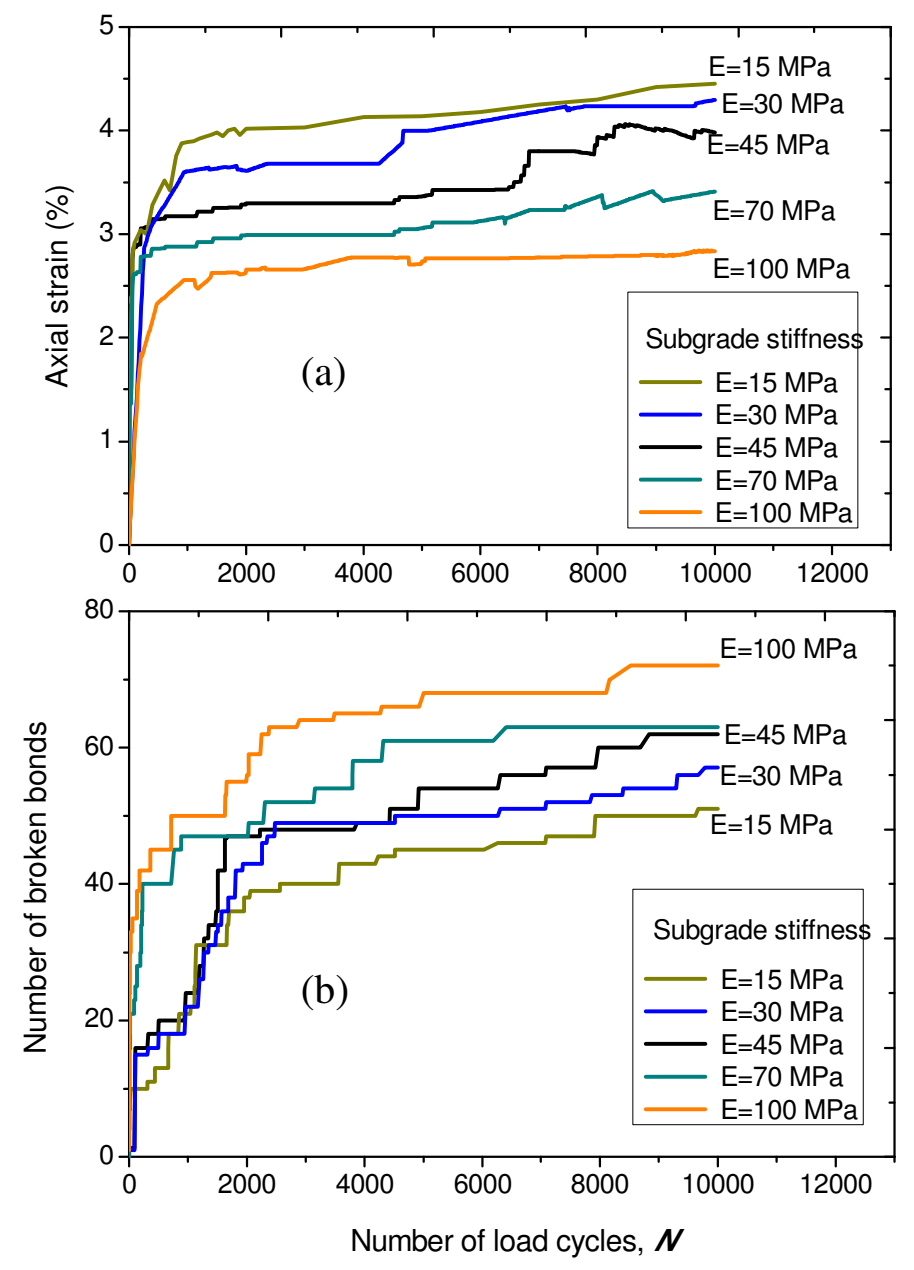

585 Fig. 8. Effect of subgrade modulus on: (a) axial strain; (b) number of bond breakage. 

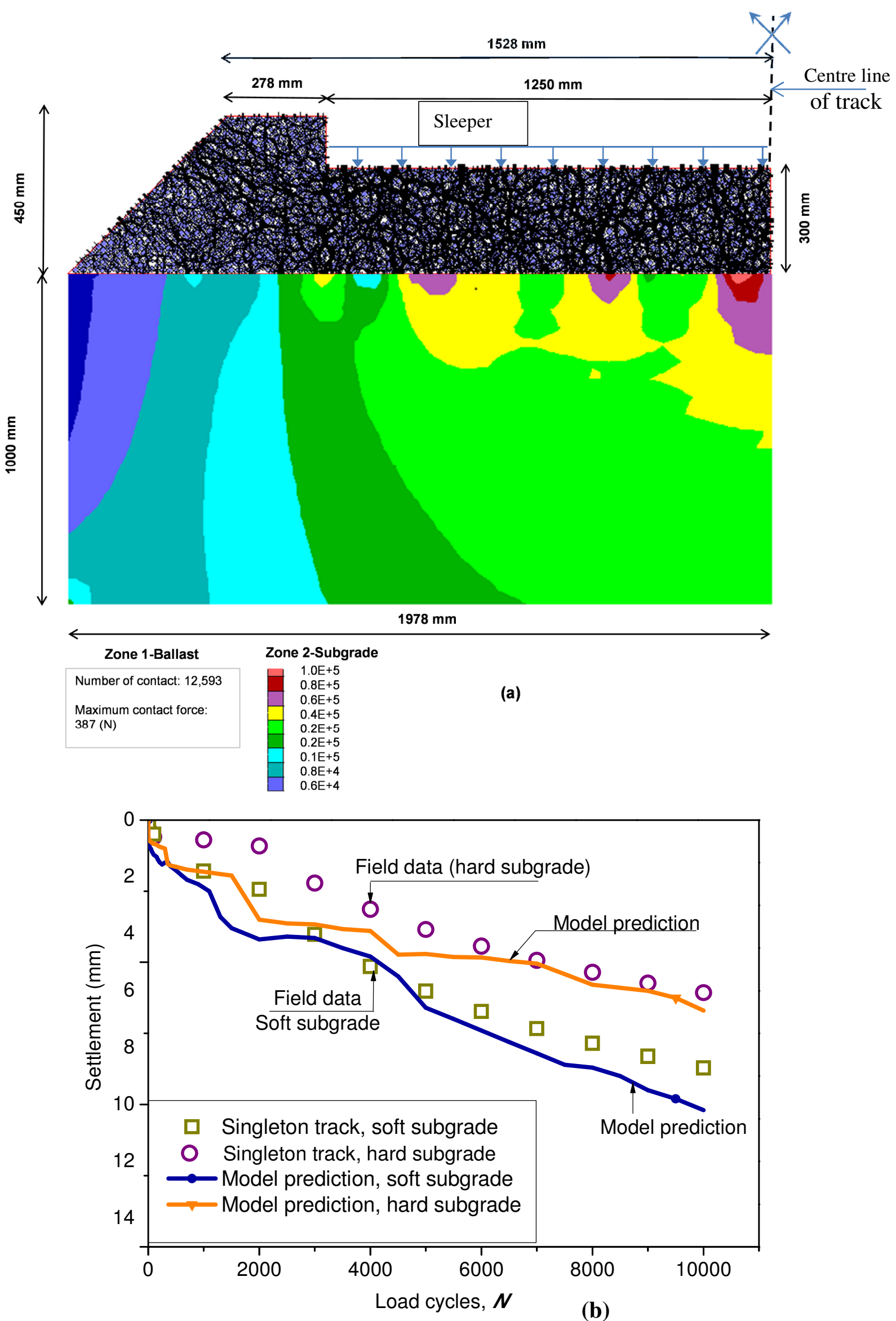

589 Fig. 9. Half- track model on the Singleton track: (a) contact force in ballast and vertical stress 590 contour in subgrade (unit in Pascal); (b) comparisons of settlement between the combined model 591 and field data. 

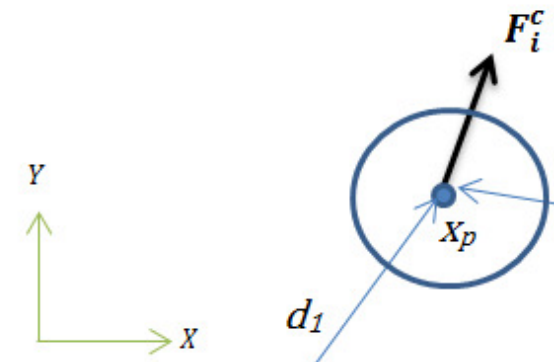

$F_{i}^{c}$

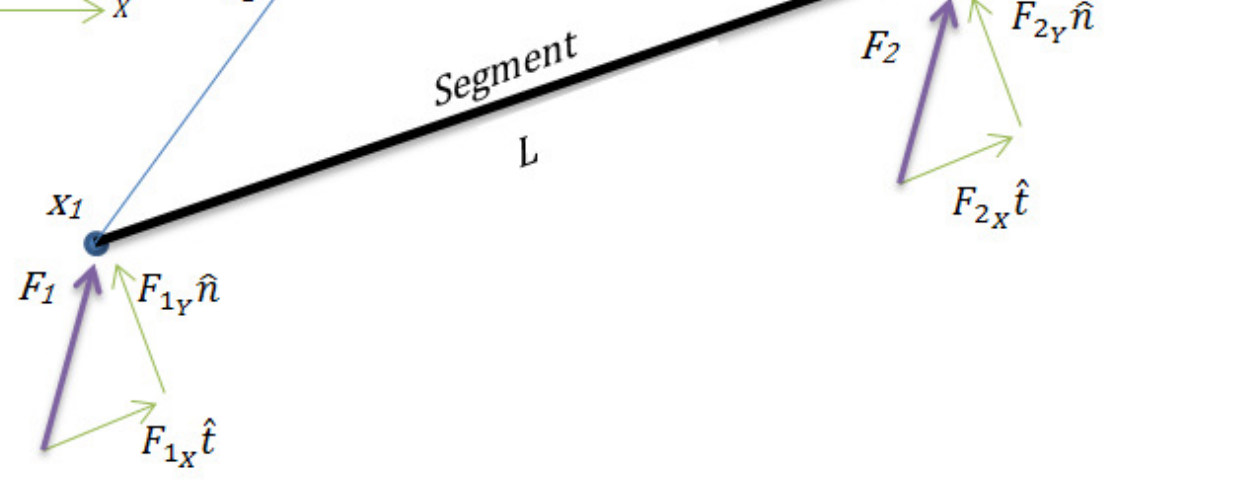

Fig. 10. Interface element: mapping particle contact force to segment end points 